\title{
Investigating the relationship between perceptions of social responsibility and community resilience to flooding: a definition, context and methodology
}

\author{
A. Mullins \& R. Soetanto \\ Department of Built Environment, Coventry University, UK
}

\begin{abstract}
Despite well-documented evidence of the potential physical impacts of flooding, research has so far neglected to fully investigate the manner by which different aspects of decision making at community level could influence resilience to flooding. This research attempts to investigate this gap in knowledge by exploring ways in which a better understanding of the expectations associated with social responsibility could potentially increase community resilience. There is particular emphasis upon the interrelationships between social responsibility and the decision making process. This paper sets the context for this investigation and proposes a methodology that attempts to not only understand how key community groups perceive their own levels of social responsibility to the community, but also what level of social responsibility they believe the other groups should have. It is argued that community groups may not even be aware that they are failing to meet their expected level of social responsibility. Therefore, the gaps discovered by this methodology between a group's own perception and how they are perceived by others would highlight barriers to community resilience. An argument for research to better understand resilience at the level of the community by exploring the individual and interconnected decision making of householders, small businesses and policy makers, is further elaborated. The arguments presented here will be of interest to community leaders and provide considerations for built environment professionals embarking on the development of resilience measures, with considerations suggested for future research within this field.
\end{abstract}

Keywords: climate change, community resilience, decision making, risk perception, social responsibility. 


\section{Introduction}

The academic literature indicates that human activity is having a large, detrimental effect upon the environment, increasing climate change and thereby increasing the likelihood of extreme weather events, such as severe flooding [1]. In modern times, our built environments have become increasingly merged with the natural environment, making both more susceptible to flooding. Flooding has not only become more frequent and more severe, but also society has become more vulnerable to its effects. Flooding is of particular concern within the UK, and in 2007 there was widespread flooding that caused an enormous amount of damage as again our fragile infrastructure was not able to cope with such an extreme event. There is an inextricable link between people, their built environment and its relationship with flooding. The better prepared people within a built environment are, the smaller the impact the flooding is able to have. This is important because above all the forecasts and technologies of the modern age, it is argued that the people remain the key to a successful defence. Following the extreme flooding event in 2007, the Pitt review [2] acknowledged the importance of building resilience at local community level, and provided tangible evidences of how this resilience could limit the damages from flooding. However, research has so far neglected to fully investigate this area within the built environment with which we are most familiar and is most salient to our needs: our own community. This paper reports an investigation to enhance understanding of decision making processes and interrelationships between three key community groups (policy makers, householders and small businesses) in order to improve the resilience of the local community. A better understanding of social responsibility, the decision making process, and interrelationships amongst members of the community will help joined-up thinking and optimise the selection of adaptation and mitigation strategies to flooding. Firstly this paper discusses resilience and decision making at the level of the community, before exploring potential barriers and drivers for community resilience through a greater understanding of social responsibility. This paper details the proposed methodology for investigating this area and concludes with considerations for further research.

\section{Community resilience}

Many definitions of resilience describe communities dealing with the effects of a flooding event and then returning to their normal functioning prior to the event. However, if a community returns to its previous state then it may have bounced back from the event but it has not actually increased its resilience to similar events. Instead, resilience must be thought of as containing elements of learning and adaptation to events so that community resilience can be increased. The resilience of a community is determined by the interconnected system's ability to absorb disturbance, self-organise and contain the capacity to learn and adapt [3]. It is the attitudes, perceptions and behaviours that members of a community adopt or display prior to a flooding event that can determine the ability of that 
community to absorb the disturbance. Furthermore, these aspects also determine their motivation and ability for self-organisation during the event and how much they are willing to learn from the event in order to change their perceptions and behaviours.

There has been research conducted on a number of aspects of extreme flooding events and climate change, such as resilience, adaptive capacity and vulnerability at the national, regional and sector levels [4], but there has been very little research conducted within the heart of our built environments, at the local community level. As a conceptual framework, it is helpful to understand a community in geographical terms as the members of these communities not only share the resources of that area but also have a shared risk of hazards. Furthermore if members of these communities share common resources and hazards it may be easier to identify the differences between individuals that possess different levels of engagement with the issue of climate change. A localised approach will provide a better context for understanding the decisions of members of the community who fail to engage in resilience promoting actions. Lorenzoni and Pidgeon [5] support this view, stating that although there is concern regarding climate change present in Europe and the USA; it is not a high enough concern to change behaviours in daily lives and therefore saliency of risk must be increased by concentrating communication of risk at the community level.

There are four main stages to the resilience process, collectively known as the social resilience cycle [6]. The first stage is mitigation where there is a general process of increasing a community's ability to cope with a flooding event, for example by not building on flood plains or by better protecting buildings. The decisions associated with this stage are the planning and preparation decisions made before the flooding occurs, such as training staff, which provide a basis for community resilience to the flooding event. This first stage is arguably the most crucial stage in determining the degree of resilience that a community will have to a flood as it can also affect the capabilities of the later stages. The first stage is also the phase where perceptions, beliefs and other human barriers can create the most diverse behaviour, as trying to convey the dangers of a flood which has not yet occurred is infinitely more difficult than pointing out the danger and destruction that surrounds people in the later stages. Therefore, these potential barriers to resilience need to be better understood.

\subsection{Key community groups}

The continued successful resilience of the community in the short to medium term relies upon the groups which make up that community, such as the householders, small and medium-sized enterprises (SMEs) and policy makers. Communities are made up of individuals, each of whom can have an effect upon their personal level of resilience to flooding, which in turn will have an effect upon their community resilience. Individuals have a responsibility then to increase their resilience and they can do so through their lifestyle choices and the decisions they make about being aware of the risks faced by their community. Unfortunately, many people are unaware or are in denial about the risks they live 
with each day. It is these counterproductive attitudes and flawed decision making which needs to be changed in order to increase resilience. In order to instigate the necessary changes, researchers need to firstly understand how and why people reach the decisions they do about the risk of flooding, as well as understanding how the interdependencies within the community and societal infrastructure as a whole can affect these decisions. For example, why do local policy makers make the decision to build houses on flood plains when they know that this decreases their community resilience to an extreme flooding event? Why do householders and businesses make the decision to occupy buildings on flood plains when they know that this decreases their personal resilience to an extreme flooding event?

The example above indicates that there is a lack of understanding of individual and social responsibility being taken for actions that can affect personal, community and national resilience to flooding, and tension between competing factors influencing decisions. We may live in a modern blame culture but there appears to be a lack of accountability for the tragedies that occur when the effects of disasters are increased because individuals have to make less than optimum decisions that have decreased their resilience to such events. Is it the fault of householders who choose to live there or the fault of policy makers who allow people to build there? Too often flooding events are blamed on being an 'act of God' when in fact a clear pathway of poor decisions made over a long period of time have contributed to the final damage caused by these events. Furthermore the over reliance upon others that is fostered through our modern interdependent lifestyles can also contribute to attitudes, decisions, expectations and behaviours which are detrimental to our resilience. The over reliance upon the emergency services can leave vulnerable situations throughout the community. Therefore, individuals need to play a greater role in increasing both their personal and community resilience to ensure that in the future communities will be better protected against these events. However, before we can change behaviour we must first overcome the perceptual barriers that affect our decision making.

\section{Perceptions of risk in decision making}

In the US, personal responsibility is recognised by the Federal Emergency Management Agency as being the key to building a resilient community. It has been shown though that households, SME's and policy makers underestimate risks that appear distant or global, such as the risk of extreme flooding events which are rare [7]. Communities not fully acknowledging the information available and thereby not acknowledging the risk or understanding their roles and responsibilities has been seen in studies in the USA, Canada and Europe [8]. Particular community groups may not even acknowledge that they have any roles or responsibilities towards flooding events or community resilience at all, as even simple denial of the risk has been found to justify lack of action on climate change [9]. There are many different perceptions of the risks posed by flooding, with some people suggesting that immediate action should be taken, others 
suggesting that the scientific evidence is unreliable, or given the uncertainty nothing should be done until there is more reliable evidence, or simply not believing that climate change affects their lives in any way [5]. Therefore, how much people believe they are at risk of flooding may determine their behaviour in preparing against such a disaster. Given then that perceptions of risk are not well understood or even accepted by many community stakeholders then it is reasonable to suggest that perceptions of roles and responsibilities relating to this risk may contain both conceptual and behavioural aspects which are detrimental to community resilience.

This makes the issue of flooding a particularly complicated concern for people making decisions as individuals, organisations, communities and society as a whole. Given that modern society contains masses of interdependencies to function efficiently, it will require an appreciation of further interconnectedness, in the form of joined-up-thinking between key community groups, to efficiently increase community resilience. This need for integration is reflected in community resilience models [10] which have stressed the importance of participation and the need to integrate stakeholders. This is further emphasised by the need to integrate community groups within climate change education. Top down information (policy makers telling people what should be done) does not appear to be working and therefore bottom up information (community groups integrating information together) is suggested to improve risk communication and community resilience [11]. Several main activities of Local Resilience Forums in the UK regions are to raise awareness of flooding risks, to enhance flood warnings before flooding, and to provide information of welfare needs once flooding has receded, at local community level [2]. However, there are many emotional and psychological obstacles which hamper interconnected decision making and resilience measures. These support the overall view that it is the decisions we make about our behaviour, whether it be as individuals or as part of a team, which creates the largest obstacle to successful measures to deal with flooding. The decision making process of individuals is recognised as being a vital part of community resilience. However, a number of factors can negatively affect the decision to engage with the issue. Therefore it is imperative that research identifies the most important of these factors and attempts to combat their negative effects upon the decision making process so that improved non-technical resilience measures can be proposed. We will now explore social responsibility as one of the main factors that contains the potential to affect the decision making process.

\section{Social responsibility}

One of the main areas to emerge from the discussion of resilience is the idea of individuals being more socially responsible and accepting a greater level of individual responsibility for community resilience. Therefore exploring perceptions of social responsibility for flooding will provide an excellent platform from which to investigate barriers and drivers to community resilience. 
It is important though to understand the concept of social responsibility and how it may be used as a research tool.

\subsection{Social responsibility as a concept}

Social responsibility is a term that has been utilised in a variety of forms but is widely recognised as relating to the relationships between the economic, environmental and social aspects of an organisation or groups activities that endeavour to benefit society [12]. It is largely agreed that social responsibility is an important topic not only for the business environment but also for wider society, with negative effects, such as new legislation and adverse publicity, seen as arising from a failure to recognise and maintain a suitable level of social responsibility [13]. Understanding how people perceive themselves and each other in relation to a particular aspect can be a useful way of investigating that aspect itself. This raises the question of how do these three key community groups view each other's roles and responsibilities and are there any gaps between expectations of others and understanding of one's own role? These gaps would represent potential barriers to increasing community resilience.

\subsection{Social responsibility as a research tool}

When investigating social responsibility research has largely focused on how businesses attend to societal needs through corporate social responsibility (CSR), however it could be argued that this has largely been an investigation of public relations rather than actually exploring the processes associated with social responsibility. Corporate social responsibility and public relations share such strong similarities in their origins, theories and practices that the distinction between the two fields has become blurred. It has even been stated that public relations is simply the practice of social responsibility, despite there being key differences between these two fields [14]. Therefore when one thinks of social responsibility they think of the responsibility that businesses have to the general public and how they communicate information to the public and act upon the feedback $[15,16]$, however this may actually be a more fitting description of the foundations of public relations models, such as the four step management process [17] and the RACE framework [18], rather than social responsibility. Even the foundations of CSR models themselves, such as the four-step process of corporate social involvement [19], may not be suitable to investigate the relationship between social responsibility and community resilience. This is because CSR models are built with the purpose of being related to the business, with the public being a part of this particular business process. CSR is influenced by a number of driving actors, such as investors, consumer demand, government regulation, supply chain requirements and civil groups, all of which apply in varying degrees to different businesses [14].

However, when investigating community resilience it is not solely the community group's responsibilities to each other which is being investigated, but is instead largely focused upon their responsibilities to the community itself and their roles within it. This is an important distinction that highlights the 
differences between social responsibility as an independent aspect, rather than CSR, which is a business orientated view of social responsibility, and public relations models, which although do allow a two-way flow of information are not suitable for climate change research as they do not provide true equality and integration between multiple community groups as again they have been created for a different purpose. It is unknown therefore whether or not the drivers identified for social responsibility in a corporate context will apply to perceptions of social responsibility in relation to climate change and this paper proposes a different use of social responsibility as a research tool.

Given then that community resilience to flooding relies upon the successful integration of each of the three key stakeholder groups, householders, SMEs and policy makers, then it is reasonable to suggest that social responsibility research should not be conceptualised or investigated as a circular process (see figure 1, illustration on the left), as this limits integration, which this paper suggests is a necessary component of future resilience measures. Social responsibility research instead needs to investigate perceptions of the roles and responsibilities that the key community groups have not only of themselves, but also how they perceive the other groups, with new ideas generated and communicated by each of the groups rather than the public simply providing feedback on business ideas or policies, creating a multi-path framework of perceptions and providing a basis for integration (see figure 1, illustration on the right).
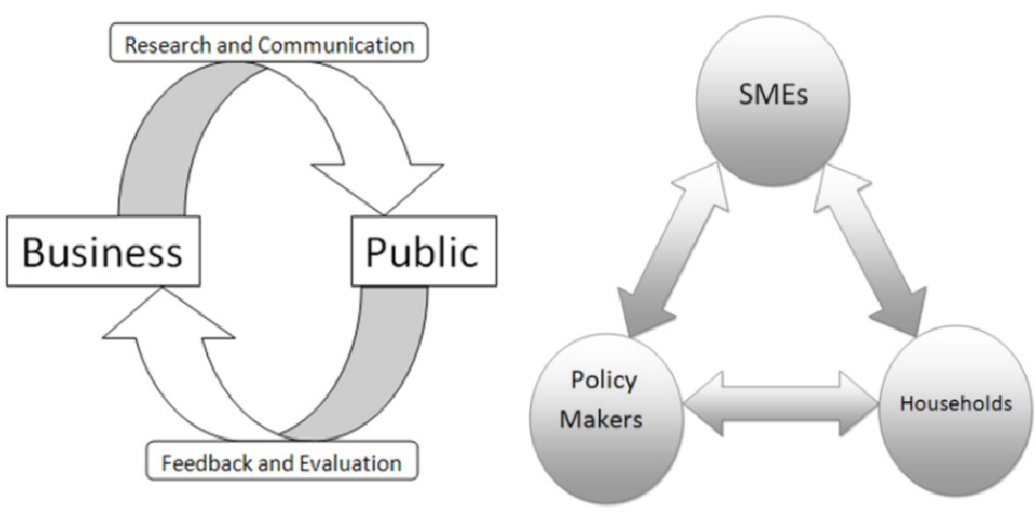

Figure 1: Public relations process vs. community social responsibility framework.

Exploring social responsibility in this integrated manner will highlight potential links between these community groups, how they are contextualised by social responsibility and how this may affect overall community resilience. For example, it is reasonable to state that householders may expect policy makers to do everything they can to prevent flooding and policy makers may expect householders to do everything they can to lessen the impact if it does flood. This 
point was also raised by the Pitt Review [2] in that the responsibility does not rest solely on the UK Government and other relevant authorities as they cannot protect the community from all consequences of disasters. However history has shown us that householders do not do anything until it is too late, such as ignoring flood warnings due to experience of false alarms, and when it does go wrong they then shift the responsibility to the policy makers. But the policy makers have to follow procedures which often assume that the householders are taking actions to lessen the impact of flooding. It is these kinds of gaps and misunderstanding of social responsibilities that can cause failings in resilience measures and drain extra resources. The householders are blaming the policy makers when in fact they have decreased their own resilience (by not taking actions to protect themselves) and their community's resilience (by allowing the flood to cause greater damage and thereby using up more of the limited resources available). Current perceptions of social responsibility need to be understood to identify these gaps and misunderstandings so that attitudes and expectations can be changed and resilience improved. These gaps would not be highlighted simply by only asking each group about their perceptions of their own responsibilities and therefore this integrated approach needs to be adopted.

\section{Methodology}

The methodology proposed is designed to explore perceptions of social responsibility within and between community groups, with the objective of highlighting potential barriers or drivers for community resilience. The investigation will use a mixed methodological approach, with questionnaires providing quantitative data regarding perceptions of social responsibility and open-ended interviews providing qualitative data. This design allows the questionnaire responses to provide an overview of perceptions of social responsibility within and between community groups and the interview responses to provide more specific details about the relationships between community groups and place the broader perceptions in context.

The study will use participant information sheets and consent forms for the questionnaires and interviews to provide details about why the research was being conducted, what was expected of the participants, providing contact details of the researchers and informing participants of their rights regarding participation and data use. The study will use four versions of a Perceptions of Social Responsibility Questionnaire, one containing questions about the self, one relating to householders, one to SMEs and one to policy makers. These questionnaires are based upon a modified version of Berkowitz and Lutterman's [20] Social Responsibility Questionnaire which has provided a valid and reliable basis for researching social responsibility since its creation. Modified versions of the original questionnaire have been used in research informing social responsibility scales [21], exploring ethics and social responsibility in relation to grocery shopping [22], testing attitudes in relation to social involvement models [23] and exploring psychosocial factors that influence volunteer work [24]. 
In the same way that Berkowitz and Lutterman [20] describe participation of individuals in society as leading to greater adoption of that society's attitudes and values, so too can it be reasonably expected that a householders, SME manager's or policy maker's role within a community be likely to lead to adoption of community norms. This is achieved through both laws and social rewards for meeting the expectations of those roles within the community; however it is unknown exactly what perceptions and behaviours these expectations create within the mindset of each community group for any given aspect of the community, for example during an extreme flood within the community. The original Social Responsibility Questionnaire measured an individual's acceptance of the traditional values of their society. The aims of this project though are to reflect the perceptions of a community group in relation to a particular aspect and as such the original attitudinal statements were modified to meet the aims of the research.

All four versions of the modified Social Responsibility Questionnaires will use the 12 modified attitudinal statements, with the terminology regarding the 'self' in the self-perception questionnaire being directed towards householders, SMEs or policy makers in their respective questionnaires. The statements will be scored using a 4 point Likert scale ranging from Strongly Agree (4) to Strongly Disagree (1), with a number of statement being reverse scored to counter acquiescence. This will give each questionnaire a potential score range of between 12 (representing very low social responsibility) and 48 (representing very high social responsibility). These attitudinal questions will provide information about how each community group views their own social responsibility and how socially responsible they perceive the other two community groups to be.

In order to provide a context for the perceptions of social responsibility highlighted by the questionnaires, an open-ended social responsibility interview schedule will be designed to facilitate cognitive mapping interviews. Cognitive mapping is a technique used to structure and evaluate accounts of problems and previous research has utilised cognitive mapping to explore decision making processes at both a micro level for individual problem solving [25] and at a macro level for corporate strategy development [26], as well as to investigate related issues such as risk [27]. Cognitive maps are a widely used validated research tool for exploring representations of knowledge of particular subjects, problem solving, decision making and representing attitudes [28].

Cognitive mapping will be used as a tool to record information gathered from interviews, achieved by recording phrases used by the interviewees under particular headings. These headings become concepts which are presented in a visual format displaying their relevant connections and interactions, revealing patterns of reasoning [26]. Cognitive mapping produces a representation of how an individual views a particular problem topic, in this instance their own or others social responsibility. It also involves the noting of opposite poles of information to help explain the meaning of particular concepts and the identification of possible options and outcomes within pairs of concepts, highlighting conflicts between different individuals [26]. Furthermore, the 
grouping of cognitive maps also allows individuals to see where their view stands in relation to others, increasing deeper understanding of the topic and highlighting gaps or potential alternatives to existing measures [26]. Cognitive maps of the resilience of individual community groups could be merged to create a collective map of community resilience. These qualities make it a useful tool for exploring perceptions of social responsibility both within individual community groups and between community groups.

\section{Conclusion}

Climate change is a serious threat and extreme weather events, such as severe flooding, are becoming more frequent within the UK. It is important that communities find new ways to increase community resilience to such events and it is proposed that the three community groups that will play a key role in this aspect are householders, SMEs and policy makers. Current community resilience models and research in the area have highlighted social responsibility as a potential factor that affects resilience levels and this research proposes that further exploration of this aspect may highlight potential barriers and drivers for community resilience. This will be achieved by using an inter-relational framework for exploring social responsibility within and between these three key community groups. With this, we can investigate current self-perceptions of social responsibility of key community groups, investigate current perceptions of social responsibility between key community groups and explore the relationship between perceptions of social responsibility and community resilience in relation to flooding. This paper proposed a methodology which investigates social responsibility in this way. The gaps between the expectations a community group has of meeting its own social responsibilities and the expectations other groups have of that group will be indicative of barriers to resilience. This is because either social responsibilities are not being met by that group or are being wrongly attributed to that group within the perceptions held by the other groups. The results will provide a deeper insight into the affect that different perceptions of social responsibility may have upon the wider issue of community resilience. It is believed that the findings will further highlight the need for integration between community groups and will be of use to community leaders (e.g. Local Authorities and Local Resilience Forums including various local flood action groups) to make better decisions regarding community resilience measures.

Future research in this area must consider that many social and psychological factors may not be distinct from each other and may influence and affect each other, as well as the overall decision making process, rather than simply being a correlation between the two aspects of social responsibility and community resilience. This paper has focused on the first stage of the social resilience cycle, but future research should also consider the effects that improved social responsibility may have upon the other stages. One of the first tasks faced by researchers though is establishing a common framework for measuring social responsibility within the community. There is much work to be done in this field, but what can be concluded is that the role of perceptions of social responsibility 
are extremely important when trying to protect our built environments from flooding disasters.

\section{References}

[1] IPCC - Intergovernmental Panel on Climate Change, Climate change 2001. Impacts, Adaptation, and Vulnerability. Cambridge University Press: Cambridge, 2001.

[2] Pitt, M., The Pitt Review - Learning Lessons from the 2007 Floods. London: Cabinet Office, 2008.

[3] Walker, B. \& Salt, D., Resilience Thinking. Island Press, 2006.

[4] Gallopin, G. C., Linkages between vulnerability, resilience and adaptive capacity. Global Environmental Change, 16, pp. 293-303, 2006.

[5] Lorenzoni, I. \& Pidgeon, N., Public views on climate change: European and USA perspectives. Climatic Change, 77(1-2), pp. 73-95, 2006.

[6] Maguire, B. \& Hagan, P., Disasters and communities: understanding social resilience. The Australian Journal of Emergency Management, 22(2), pp. 16-20, 2007.

[7] Viscusi, W. \& Zeckhauser, R., National survey evidence on disasters and relief: Risk beliefs, self-interest, and compassion. Journal of Risk and Uncertainty, Springer, 33(1), pp. 13-36, 2006.

[8] Bord, R. J., O'Connor, R. \& Fisher, A., In what sense does the public need to understand global climate change? Public Understanding of Science, 9, pp.205-218, 2000.

[9] Stoll-Kleemann, S., O’Riordan, T. \& Jaeger, C. C., The psychology of denial concerning climate mitigation measures: evidence from Swiss focus groups. Journal of Global Environmental Change, 11, pp. 107-117, 2001.

[10] Paton, D., Measuring and monitoring resilience in Auckland. GNS Science Report 2007/18, 2007.

[11] Dufty, N., A New Approach to Flood Education. Molino Stewart Pty Ltd: Parramatta, 2008.

[12] ISO, ISO to go ahead with guidelines for social responsibility, Press Release 924, 29 June 2004. Geneva: International Standard Organization, 2004.

[13] Peterson, R. T. \& Jun, M., Perceptions on Social Responsibility: The Entrepreneurial Vision. Business Society OnlineFirst, 2007. http://bas.sagepub.com/cgi/rapidpdf/0007650307305758v1

[14] Clark, C. E., Differences between public relations and corporate social responsibility: an analysis. Public Relations Review, 26(3), pp. 363-380, 2000.

[15] Joyner, B. E., \& Raiborn, C. A., Management caveats for measuring and assessing public responsibility performance. Business Horizons, 48(6), pp. 525-533, 2005.

[16] Trainer, T., Social responsibility: The most important and neglected problem of all? International Journal of Social Economics, 32(8), pp. 682$703,2005$. 
[17] Cutlip, S. M. \& Center, A. H., Effective Public Relations (5th ed.). Englewood Cliffs, NJ: Prentice-Hall, 1978.

[18] Marston, J. E., Modern Public Relations. New York: McGraw-Hill, 1979.

[19] Preston, L. E. \& Post, J. E., Private Management and Public Policy: The Principle of Public Responsibility. Englewood Cliffs, NJ: Prentice-Hall, 1975.

[20] Berkowitz, L. \& Lutterman, K. G., The traditional socially responsible personality, Public Opinion Quarterly, 32, pp. 169-185, 1968.

[21] Reed, V. A., Jernstedt, G. C., Hawley, J. K., Reber, E. S., \& DuBois, C., Effects of a small-scale, very short-term service learning experience on college students. Journal of Adolescence, 28, pp. 359-368, 2005.

[22] Megicks, P., Memery, J. \& Williams, J., Ethics and Social Responsibility Issues in Grocery Shopping: An A Preliminary Typology. Qualitative Marketing Research, 8(4), pp. 399-412, 2005.

[23] Frieden, J. B. \& Downs, P. E., Testing the Social Involvement Model in an Energy Conservation Context. Journal of the Academy of Marketing Science, 14(3), pp. 13-20, 1986.

[24] Chacon, F., Menard, M., Sanz, M. \& Vecina, M. L., Psychosocial Factors That Influence Volunteer Work: A Pilot Study. Psychology in Spain, 2, pp. 108-115, 1998.

[25] Eden C., Working on problems using Cognitive Mapping. In S. Littlechild, and M. Shuttler (Eds). Operational Research in Management. Prentice Hall: London, 1991.

[26] Eden, C. \& Ackermann, F., Making Strategy: The Journey of Strategic Management. London: Sage, 1998.

[27] Harris, C., Daniels, K. \& Briner, R. B., Using Cognitive Mapping for Psychosocial Risk Assessment. Risk Management, 4(3), pp. 7-21, 2002.

[28] González, F. M., Morón, C. \& Novak, J. D., Errores conceptuales. diagnosis, tratamiento y reflexiones. Madrid: Morata, 2001. 